\title{
Altered vascular contractility in adult female rats with hypertension programmed by prenatal glucocorticoid exposure
}

\author{
P W F Hadoke, R S Lindsay, J R Seckl, B R Walker \\ and $\mathbf{C} \mathbf{J}$ Kenyon
}

Endocrinology Unit, Centre for Cardiovascular Science, University of Edinburgh, The Queen's Medical Research Institute, Edinburgh EH16 4TJ, UK
(Requests for offprints should be addressed to P W F Hadoke, Endocrinology Unit, 2nd Floor O.P.D., Western General Hospital, Crewe Road,
Edinburgh, EH4 2XU, UK; Email: phadoke@staffmail.ed.ac.uk)
(R S Lindsay is currently at BHF Cardiovascular Research Centre, University of Glasgow, Gardiner Institute, 44 Church Street, Glasgow G12 6NT, UK)

\begin{abstract}
Excessive exposure to glucocorticoids during gestation reduces birth weight and induces permanent hypertension in adulthood. The mechanisms underlying this programmed elevation of blood pressure have not been established. We hypothesised that prenatal glucocorticoid exposure may lead to vascular dysfunction in adulthood. Pregnant rats received dexamethasone (Dex) $(100 \mu \mathrm{g} / \mathrm{kg}$, s.c.) or vehicle (control) daily throughout pregnancy. Blood pressure was elevated (students $t$-test, unpaired; $P<0 \cdot 05$ ) in adult female offspring (aged 12-16 weeks) of Dex-treated mothers $(148 \cdot 0 \pm 3 \cdot 6 \mathrm{mmHg}, n=10)$ compared with the control group $(138 \cdot 0 \pm 2 \cdot 5 \mathrm{mmHg}, n=8)$. Vascular responsiveness in aortae and mesenteric arteries was differentially affected by prenatal Dex: aortae were less responsive to angiotensin II, whereas mesenteric arteries were more responsive to norepinephrine, vasopressin and potassium (mesenteric arteries respond poorly to angiotensin II in vitro). Acetylcholine-mediated, endotheliumdependent relaxation was similar in both groups.
\end{abstract}

Prenatal exposure to Dex had no effect on blood pressure or aldosterone response to acute (15 min, i.v.) infusion of angiotensin II (75 ng/kg per min). In contrast, chronic (2-week, s.c.) infusion of angiotensin II $(100 \mathrm{ng} / \mathrm{kg}$ per min) produced a greater elevation $(P<0.05)$ of blood pressure in Dex-treated rats $(150 \cdot 0 \pm 3.6 \mathrm{mmHg})$ than in controls $(135 \cdot 3 \pm 5 \cdot 4 \mathrm{mmHg})$, and aldosterone levels were higher in Dex-treated animals. There was no angiotensin II-induced medial hypertrophy/hyperplasia in mesenteric arteries from Dex-treated rats. These results indicate that vascular function is altered in a region-specific manner in rats with glucocorticoid-programmed hypertension. Despite a striking increase in mesenteric artery contraction in Dex-treated rats, in vivo studies suggest that abnormalities of the renin-angiotensin-aldosterone system, rather than enhanced vascular contractility, may be responsible for the elevation of blood pressure in these animals.

Journal of Endocrinology (2006) 188, 435-442

\section{Introduction}

Prenatal 'programming' of physiological responses (Barker et al. 1993), which could explain the association of low birth weight with increased risk of cardiovascular and metabolic disease in adulthood (Barker et al. 1990), has been attributed to several factors, including dietary modification (Langley-Evans et al. 1994, Woodall et al. 1996) and maternal stress during pregnancy (Lesage et al. 2001). Excess exposure of the foetus to glucocorticoids may provide a common mechanism for the programming response (Edwards et al. 1993). Indeed, in rats, maternal undernutrition produces a rise in maternal cortisol (Fowden 1995) and impaired glucocorticoid inactivation in the placenta (Langley-Evans et al. 1996, Nyirenda \& Seckl 1998, Lesage et al. 2001). Furthermore, the link between glucocorticoids and adult hypertension is well established, with prenatal glucocorticoid administration (to rats and sheep) inducing low birth weight, impaired glucose tolerance and elevated blood pressure in adult offspring (Benediktsson et al. 1993, Lindsay et al. 1996, Dodic et al. 1998).

The mechanisms by which prenatal programming induces adult hypertension have not been established. One possibility is that changes in peripheral vascular function contribute to elevation of blood pressure; indeed, enhanced contractility has been demonstrated in femoral arteries isolated from rats exposed to maternal dietary restriction (Ozaki et al. 2001). Glucocorticoids could be implicated in programming of vascular function since they alter the function of both endothelial (Johns et al. 2001) and vascular smooth muscle cells (Ullian et al. 1996, Souness et al. 2002). Consequently, infusion of the synthetic glucocorticoid betamethasone elevates blood 
pressure and alters vascular contractile and dilator function in preterm lambs (Gao et al. 1996. Anwar et al. 1999, Docherty et al. 2001). The effects of these interactions may extend into later life as prenatal exposure results in permanent changes, such as elevated glucocorticoid receptor expression in adult rats (Nyirenda et al. 1998), in glucocorticoid signalling pathways.

We tested the hypothesis that prenatal exposure to glucocorticoids in rats results in altered vascular function in adult offspring. We used an established model of glucocorticoid-mediated, programmed hypertension (Benediktsson et al. 1993) to determine whether exposure to the synthetic glucocorticoid dexamethasone (Dex) in utero produced: 1) altered contractile and relaxant function in isolated (conduit and resistance) arteries in vitro and 2) altered vasopressor response in vivo. We investigated only female offspring, as recent studies (Khan et al. 2003, Ortiz et al. 2003) and our own experience (O'Regan et al. 2004) suggest that females are more likely to develop hypertension in response to prenatal programming.

\section{Materials and Methods}

\section{Rats}

As in previous studies, female Wistar rats $(200-250 \mathrm{~g}$; $n=26)$ received daily s.c. injections of Dex $(100 \mu \mathrm{g} / \mathrm{kg}$; $n=14)$ or vehicle $(0 \cdot 1 \mathrm{ml} 4 \%$ ethanol-saline $n=12)$ throughout pregnancy (Benediktsson et al. 1993). The number of pups per litter $(16 \pm 0.6$ pups from salinetreated mothers) was reduced $(P<0 \cdot 02)$ by prenatal Dex $(13 \pm 0.9$ pups from Dex-treated mothers), but the ratio of males to females was unaffected. This was accompanied by a reduction $(P<0.01)$ in pup weight $(3.77 \pm 0.03 \mathrm{~g}$ in the saline group vs $3.36 \pm 0.05 \mathrm{~g}$ in the Dex group): weight reduction was seen in both male and female pups. No death was observed in either group, litters were culled to eight pups and animals were randomly selected from different litters for subsequent experimentation. Stage of cycle was not taken into account at the time that measurements were made. Experiments conformed to The Principles of Animal Care (NIH publication no. 85-23, revised 1985) and were performed under the UK Home Office Animals (Scientific Procedures) Act 1986.

\section{Materials}

Salts were obtained from BDH, Poole, Dorset, UK; norepinephrine hydrochloride (NE), angiotensin (Ang) II, arginine vasopressin (AVP) and acetylcholine chloride (ACh), from Sigma.

\section{Influence of prenatal Dex on vascular function in vitro}

Blood pressure was measured in adult female (16 weeks) offspring by tail cuff plethysmography (Evans et al. 1994), on four different days, by an operator blinded to treatment.
Rats were killed by decapitation. Functional assessment of aortae and mesenteric arteries was performed by standard organ bath (Martin et al. 1986) and small-vessel myograph (Falloon et al. 1995) techniques respectively. Isometric force was measured in vessels suspended in physiological salt solutions (PSS) at $37{ }^{\circ} \mathrm{C}$, perfused with carbogen. The arteries were equilibrated at their optimum resting settings (2.0 g (Martin et al. 1986) and 0.9 L100 (Falloon et al. 1995)) and subjected to a standard start procedure (Martin et al. 1986, Falloon et al. 1995).

Protocol Cumulative concentration-response curves were obtained with NE $\left(10^{-9}-3 \times 10^{-6} \mathrm{~mol} / 1\right.$ for aortae; $10^{-9}-3 \times 10^{-5} \mathrm{~mol} / 1$ for mesenteric artery), potassium $\left(\mathrm{KCl} ; 2.5 \times 10^{-3}-3.2 \mathrm{~mol} / 1\right.$ for aortae; high-potassium PSS (KPSS), $2.5 \times 10^{-3}-0 \cdot 125 \mathrm{~mol} / 1$ for mesenteric arteries), Ang II $\left(10^{-11}-1 \times 10^{-6} \mathrm{~mol} / \mathrm{l}\right)$ and $\operatorname{AVP}\left(10^{-11}-1 \times 10^{-6}\right.$ $\mathrm{mol} / \mathrm{l})$. Responses to the endothelium-dependent vasodilator ACh $\left(10^{-9}-3 \times 10^{-5} \mathrm{~mol} / \mathrm{l}\right)$, were obtained after contraction with sufficient NE $\left(3 \times 10^{-8}-10^{-5} \mathrm{~mol} / \mathrm{l}\right)$ to achieve $\sim 80 \%$ of the maximum contraction.

Influence of prenatal Dex on the pressor response in vivo

Acute Three days prior to infusion, cannulae were inserted, under halothane anaesthesia (Fluothane, Zeneca, UK), into the carotid artery of adult (12 weeks), female pups (Benediktsson et al. 1993). Blood pressure was measured directly in conscious, unrestrained rats with the Elcomatic pressure transducer (Glasgow, UK) prior to, and during, venous infusion of Ang II (75 ng/ $\mathrm{kg}$ per min for $15 \mathrm{~min}$ ) (Brown et al. 1981). Blood samples were taken for measurement of plasma aldosterone.

Chronic Blood pressure was measured in adult (12 weeks), female offspring by tail cuff plethysmography (Evans et al. 1994) on three separate days. Minipumps (Model 2002; Alzet, Cupertino, CA, USA) were implanted, under halothane anaesthesia, to infuse Ang II (Hypertensin; Ciba Geigy, Basel, Switzerland), $100 \mathrm{ng} / \mathrm{kg}$ per min, or vehicle s.c. for 2 weeks. Rats were killed by decapitation, trunk blood was collected for measurement of hormones, sections of the mesenteric arcade were fixed in $10 \%$ neutral buffered formalin for histological analysis, and tissues were retrieved and weighed.

\section{Hormone assays}

Plasma renin activity was measured as Ang I generated from plasma incubated at $37^{\circ} \mathrm{C}$ for $30 \mathrm{~min}$ (Miller et al. 1980). Ang I, corticosterone (Kenyon et al. 1993) and aldosterone (DPC, Los Angeles, CA, USA) concentrations were measured by RIA.

\section{Histological analysis}

Fixed vessels were embedded in paraffin wax and $3 \mu \mathrm{m}$ sections stained with elastic van Giessen. Image analysis 
Table 1 The influence of prenatal Dex on contraction and relaxation of aortae from adult offspring



Values are mean \pm S.E.M. and were compared by Student's two-sample $t$-test; ${ }^{* *} P=0 \cdot 01$. Sensitivity values are quoted as the - $\log$ of the concentration required to produce $50 \%$ contraction $\left(\mathrm{pD}_{2}\right)$ or $50 \%$ inhibition of precontractile tone (-log $\mathrm{IC}_{50}$ ). Ang II: angiotensin II; NE: norepinephrine; AVP: arginine vasopressin; ACh: acetylcholine.

was performed by an operator blinded to treatment, using MCID-M4 software (Imaging Research Inc, Brock University, St. Catherines, Ontario, Canada).

\section{Statistics}

Values are mean \pm S.E.M for $n$ pups from different mothers with the exception of in vivo data, where $n$ refers to number of pups from five vehicle-treated and four Dex-treated mothers. Data were analysed by two-way, one-way or repeated-measures ANOVA with Tukey's multiple-comparisons test or Student's $t$-test, as appropriate. Significance was set at $P<0 \cdot 05$.

\section{Results}

\section{Influence of prenatal Dex on vascular function in vitro}

At 16 weeks of age, female pups exposed to Dex in utero had elevated systolic blood pressure (control 138.0 $\pm 2 \cdot 5$ $\mathrm{mmHg}, n=8$; Dex 148.0 $\pm 3.6 \mathrm{mmHg}, n=10 ; P<0 \cdot 05)$.

\section{Aorta}

The sensitivity of aortic rings to Ang II was reduced by prenatal Dex exposure. A similar magnitude reduction in sensitivity to NE did not achieve significance $(P=0 \cdot 07)$ (Table 1). Maximum contractions and endotheliumdependent relaxation were unaffected by prenatal exposure to Dex (Fig. 1; Table 1).

\section{Mesenteric artery}

Mesenteric arteries from control and Dex groups were similar in size (internal diameter $282 \pm 14 \mu \mathrm{m}(n=6)$ and $274 \pm 17 \mu \mathrm{m}(n=8)$ respectively; $P=0 \cdot 74)$. Contractile responses to $\mathrm{NE}, \mathrm{KCl}$ and $\mathrm{AVP}$ were enhanced in mesenteric arteries from the Dex group (Fig. 1; Table 2). The sensitivity of the mesenteric artery to AVP (Table 2) was unaffected by prenatal Dex treatment $(P=0 \cdot 06)$. Ang II produced virtually no contraction in arteries from the Dex group and an unreproducible, spasmodic response in controls (data not shown). ACh-mediated relaxation of mesenteric arteries was unaffected by prenatal exposure to Dex (Table 2).

Influence of prenatal Dex on pressor response in vivo

Acute pressor response The elevation of basal blood pressure measured by carotid cannulation in Dex-exposed pups was again apparent (Table 3). In both groups of rats, Ang II infusion resulted in an acute rise in blood pressure evident a few seconds after the onset of the infusion (Table 3: ANOVA, $P<0 \cdot 01$ ). There was no difference, however, in the incremental rise in blood pressure in response to Ang II (control $\Delta 18 \cdot 5 \pm 6 \cdot 2$ $\mathrm{mmHg}, n=6$, Dex $\Delta 16 \cdot 5 \pm 1 \cdot 7 \mathrm{mmHg}, n=5)$.

Acute infusion of Ang II, which does not allow time for compensatory suppression of renin, increased plasma aldosterone levels 2-3-fold (Table 3; $P<0.05$ in both groups). Basal aldosterone levels were not different in control and Dex-treated groups. After Ang II infusion, there were no differences between Dex and control groups in either the absolute values of plasma aldosterone concentration (Table 3) or the incremental rise from baseline (control $\Delta 2330 \pm 526 \mathrm{pM}, \quad n=6 \quad$ vs Dex $\Delta 1888 \pm 431 \mathrm{pM}, n=5)$.

Chronic pressor response Immediately before starting treatment of 12-week-old pups, mean arterial pressure was higher in the Dex group (control 118.9 $\pm 1.4 \mathrm{mmHg}$, $n=16$; Dex 123.4 $\pm 1 \cdot 9 \mathrm{mmHg}, n=16 ; P=0 \cdot 05)$. After 7-day treatment with Ang II, blood pressure had increased in both groups $(P<0 \cdot 01)$ (Fig. 2). The Dex/Ang II group had a higher blood pressure than the control/Ang II group $(150 \cdot 0 \pm 3.6 \mathrm{mmHg}, n=8$ and $135.3 \pm 5.4 \mathrm{mmHg}, n=8$; $P<0 \cdot 05)$. The increment in blood pressure compared with pretreatment values (Fig. 2 inset) was greater in 
(a)

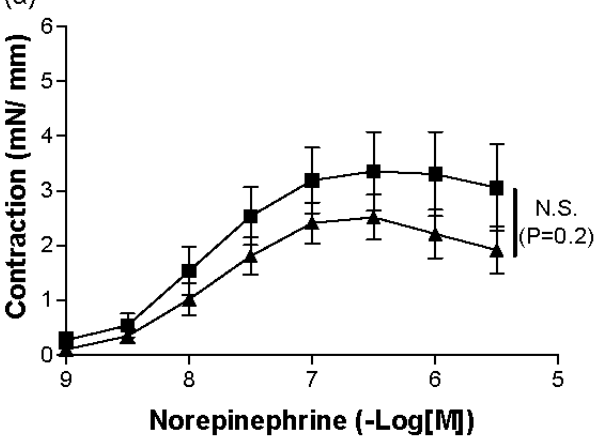

(b)

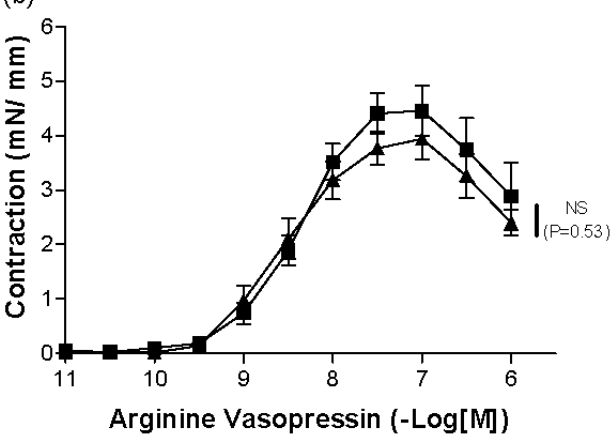

(c)

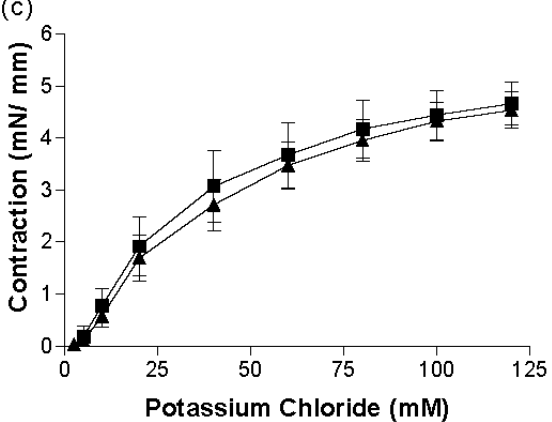

(d)

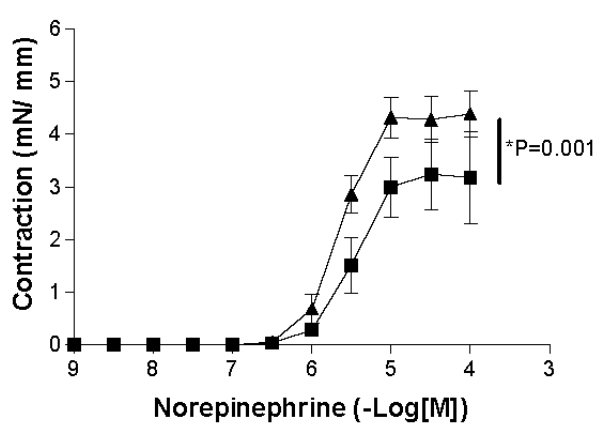

(e)
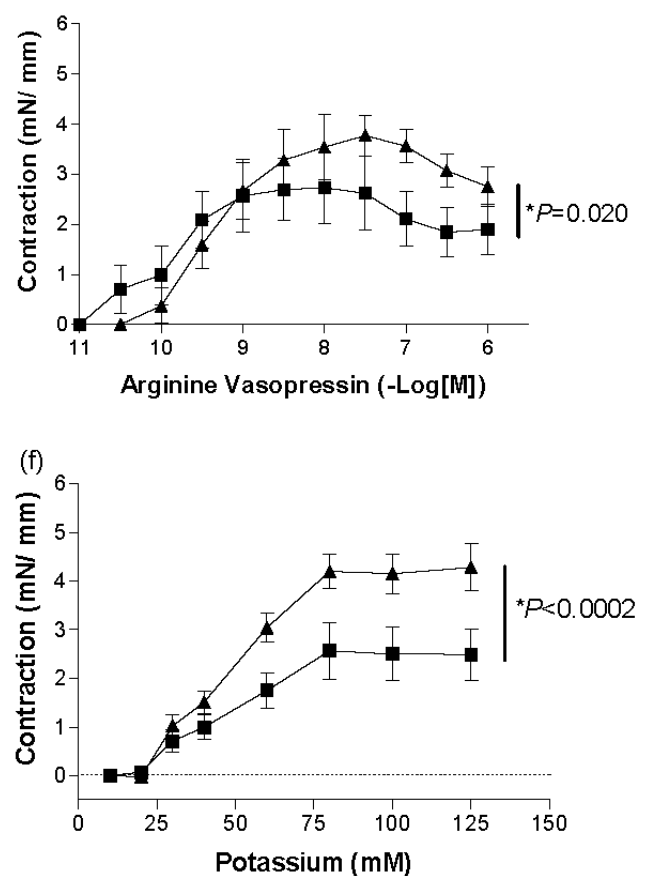

Figure 1 The influence of prenatal Dex on contractile responses of aortae and mesenteric arteries taken from adult offspring. Prenatal exposure to Dex had no effect on aortic contraction $(\mathrm{a}-\mathrm{c})$, but enhanced contractile responses to (d) norepinephrine, (e) arginine vasopressin and (f) $\mathrm{KCl}$ in mesenteric arteries ( $\boldsymbol{\Delta}$ : Dex, $n=8 ; \boldsymbol{\square}$ : control, $n=4-6$ ). Each point represents mean \pm S.E.M. Curves were compared by two-way ANOVA.

prenatal Dex-exposed rats, indicating that they were more sensitive to Ang II than the control group $(P<0 \cdot 04)$.

Plasma corticosterone levels were similar in Dex- and vehicle-exposed adult female rats and were unaltered by Ang II infusion (Table 4a). Plasma renin activity was similar in vehicle- and Dex-treated rats (Table 4a). Plasma renin suppression by Ang II was evident in control and Dex-treated groups (Table 4a); Ang II suppressed plasma renin activity (PRA) to similar levels in both groups, reflecting an $81 \%$ reduction in activity in Dex-treated animals compared with a 50\% reduction in controls.
In contrast to the acute Ang II study, the elevation of basal plasma aldosterone levels detected in Dex-treated rats was significant compared with controls, but chronic Ang II infusion did not produce a significant increase in plasma aldosterone in either group (Table 4a).

Image analysis was performed on 3-13 arteries of similar size (Table 4b) from each rat. The medial areas of mesenteric arteries from rats exposed to Dex in utero were smaller than controls (Table 4b), but no difference in medial thickness was observed between Dex and vehicle rats after chronic infusion of Ang II. These values were 
Table 2 The influence of prenatal Dex on contraction and relaxation of mesenteric arteries from adult offspring

\begin{tabular}{|c|c|c|c|c|}
\hline \multicolumn{3}{|c|}{$\mathbf{E}_{\max }(\mathrm{mN} / \mathrm{mm}$ or $\%$ maximum relaxation $)$} & \multicolumn{2}{|c|}{ Sensitivity $\left(\mathrm{pD}_{2}\right.$ or $\left.-\log I \mathrm{IC}_{50}\right)$} \\
\hline & Vehicle & Dex & Vehicle & Dex \\
\hline NE & $3 \cdot 36 \pm 0 \cdot 71(6)$ & $4 \cdot 42 \pm 0 \cdot 42(8)$ & $5 \cdot 54 \pm 0 \cdot 12(6)$ & $5 \cdot 67 \pm 0 \cdot 08(8)$ \\
\hline AVP & $2 \cdot 87 \pm 0 \cdot 72(6)$ & $4 \cdot 16 \pm 0 \cdot 40(8)$ & $9 \cdot 86 \pm 0 \cdot 15(6)$ & $9 \cdot 16 \pm 0 \cdot 27(8)$ \\
\hline $\mathrm{KCl}$ & $2 \cdot 61 \pm 0.56(4)$ & $4.52 \pm 0.53(8)^{*}$ & $1 \cdot 36 \pm 0.03$ & $1 \cdot 34 \pm 0.03(8)$ \\
\hline $\mathrm{ACh}$ & $75 \cdot 3 \pm 11 \cdot 8(6)$ & $81 \cdot 1 \pm 10 \cdot 5(8)$ & $7 \cdot 25 \pm 0 \cdot 34(6)$ & $7 \cdot 27 \pm 0 \cdot 20(8)$ \\
\hline
\end{tabular}

Values are mean \pm S.E.M. and were compared by Student's two-sample $t$-test; ${ }^{*} P=0 \cdot 03$. Sensitivity values are quoted as the - $\log$ of the concentration required to produce $50 \%$ contraction $\left(\mathrm{pD}_{2}\right)$ or $50 \%$ inhibition of precontractile tone $\left(-\log \mathrm{IC}_{50}\right)$. NE: norepinephrine; AVP: arginine vasopressin; $\mathrm{ACh}$ : acetylcholine.

reinforced by lack of differences in media:lumen ratios in saline- and Ang II-treated groups (Table 4b). Neither Dex treatment in utero nor Ang II treatment in adulthood led to changes in organ (adrenal, kidney, liver, heart and thymus) weights (data not shown).

\section{Discussion}

This investigation demonstrated enhanced contractility in mesenteric arteries, but not aortae, from rats with glucocorticoid-programmed hypertension. Functional changes in the mesenteric arteries were not, however, associated with an increase in the acute pressor response to Ang II in vivo. This suggests that increased Ang II-dependent vasoconstriction does not contribute to elevated blood pressure in these animals. Similarly, enhanced sensitivity to chronic blood pressure elevation in response to Ang II was probably the result of increased basal renin-angiotensin-aldosterone system (RAAS) activity rather than to changes in the resistance vasculature. We conclude that a non-selective, systemic change in vascular function and structure is unlikely to contribute to hypertension programmed by exposure to glucocorticoids in utero.

Glucocorticoid exposure, whether in rats in utero (Docherty et al. 2001) or to rat arteries in vitro (Ullian et al.
1996), can influence contraction by selective upregulation of contractile receptors in the vascular smooth muscle and/or by altering the production of endothelium-derived nitric oxide (Anwar et al. 1999, Johns et al. 2001). Impaired endothelium-dependent relaxation has been reported in arteries from rats after maternal dietary restriction (Lamireau et al. 2002, Khan et al. 2004, 2005). The present study, however, consistent with another recent report (Ozaki et al. 2001), found no impairment of endothelium-dependent relaxation in either aortae or mesenteric arteries from the Dex-treated rats. It is unlikely, therefore, that programmed endothelial cell dysfunction contributes to the elevation of blood pressure in this model.

Glucocorticoid-dependent changes in contractile function are agonist-dependent and involve several distinct mechanisms; increased $\alpha$-adrenergic contraction appears to be receptor-independent (Smith et al. 1987), whereas enhanced Ang II-mediated contraction is secondary to $\mathrm{AT}_{1}$-receptor upregulation (Ullian et al. 1992). Mechanisms for other agonists are less well established (Ullian 1999). In the current study, the comparison of functional results from aortae and mesenteric arteries indicates that, as in prenatal protein restriction in rats (Torrens et al. 2003) or prenatal Dex administration in sheep (Docherty et al. 2001), functional changes in Dex-programmed hypertension vary in arteries from different anatomical locations.

Table 3 Acute effects of Ang II infusion on blood pressure $(\mathrm{mmHg})$ and plasma aldosterone concentration (pM) in control and Dex rats

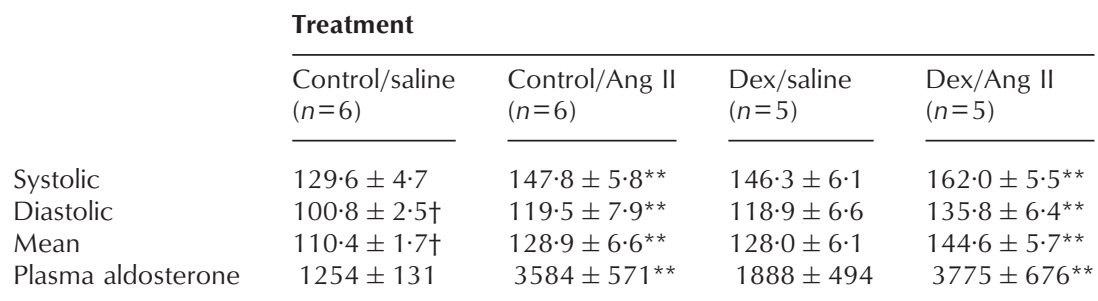

Values are mean \pm S.E.M. ${ }^{*} P<0 \cdot 01$ compared with appropriate saline-treated group and $+P<0 \cdot 05$

compared with appropriate Dex-treated group. 


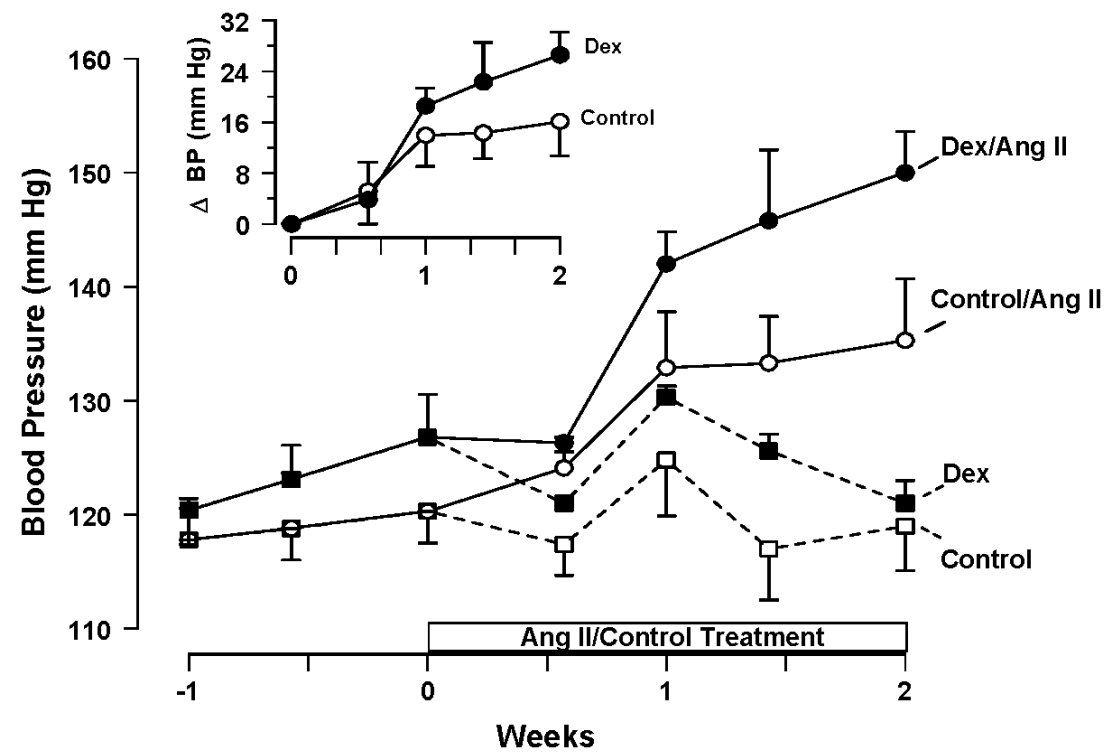

Figure 2 Serial blood pressures before (dotted lines) and after (solid lines) treatment with Ang II in adult rats exposed to dexamethasone (Dex: $-\mathbf{\square}, n=8$ ), or vehicle (control: $O / \square, n=8)$, in utero. Repeated-measures ANOVA indicates that blood pressure was significantly higher in animals treated with Dex in utero $(P<0 \cdot 05)$. Inset compares Ang II responses in Dex and control groups. Each point represents mean \pm S.E.M.

In the aorta, the failure of prenatal glucocorticoid exposure to enhance contractility (indeed, the tendency was for reduced contraction) suggests that there is no upregulation of contractile receptors in this vessel. Similarly, the enhanced contraction observed in mesenteric arteries from the Dex-treated rats was receptor-independent - the failure of Ang II to contract resistance arteries in isometric systems has been reported previously (Falloon et al. 1995). Given that endothelium-dependent relaxation is unaltered in these animals, the enhanced contraction in mesenteric arteries is probably due to changes in the vascular smooth muscle. Histological analysis indicated that structural remodelling was not a factor, suggesting, therefore, changes in post-receptor signal transduction. This would be consistent with persistence into adult life of glucocorticoid-mediated modulation of G-proteins (Haigh et al. 1990), second messengers (e.g. inositol triphosphate (Sato et al. 1992)) or sodium-calcium ion exchange (Smith \& Smith 1994).

Acute and chronic infusions of Ang II in vivo were used to assess different mechanisms of blood pressure regulation. The use of Ang II is particularly relevant, as changes

Table 4. Influence of prenatal Dex on the response of plasma hormones and mesenteric artery structure to chronic Ang II infusion

\begin{tabular}{|c|c|c|c|c|c|c|}
\hline & \multicolumn{2}{|c|}{ PRA (ng Ang l/ml per $\mathrm{h}$ ) } & \multicolumn{2}{|c|}{ Aldosterone (pM) } & \multicolumn{2}{|c|}{ Corticosterone $(\mathrm{nM})$} \\
\hline & Saline-treated & Ang II-treated & Saline-treated & Ang II-treated & Saline-treated & Ang II-treated \\
\hline $\begin{array}{l}\text { (a) Plasma hormo } \\
\text { Control (8) }\end{array}$ & $0.54 \pm 0.06$ & $0.27 \pm 0.09^{* *}$ & $990 \pm 127$ & $800 \pm 101$ & $590 \pm 77$ & $496 \pm 102$ \\
\hline $\operatorname{Dex}(8)$ & $0.64 \pm 0.07$ & $0 \cdot 12 \pm 0 \cdot 06^{* *}$ & $1171 \pm 82^{\dagger}$ & $1348 \pm 252^{\dagger}$ & $660 \pm 71$ & $624 \pm 56$ \\
\hline & \multirow{2}{*}{\multicolumn{2}{|c|}{$\begin{array}{l}\text { Artery diameter } \\
(\mathrm{mm})\end{array}$}} & \multicolumn{3}{|l|}{ Medial area } & \multirow[b]{2}{*}{ M:L ratio } \\
\hline & & & $\left(\mathrm{mm}^{2}\right)$ & (\% within exten & elastic laminae) & \\
\hline \multicolumn{7}{|c|}{ (b) Mesenteric artery structure } \\
\hline Control (4) & \multicolumn{2}{|c|}{$127 \pm 9$} & $0 \cdot 012 \pm 0 \cdot 001$ & $62 \pm 3$ & & $1 \cdot 84 \pm 0 \cdot 20$ \\
\hline Control/Ang II (4) & \multicolumn{2}{|c|}{$104 \pm 6$} & $0 \cdot 008 \pm 0 \cdot 001$ & $61 \pm 7$ & & $2 \cdot 11 \pm 0 \cdot 56$ \\
\hline $\operatorname{Dex}(4)$ & \multicolumn{2}{|c|}{$112 \pm 11$} & $0.007 \pm 0.001^{*}$ & $47 \pm 7$ & & $1 \cdot 08 \pm 0 \cdot 26$ \\
\hline Dex/Ang II (4) & \multicolumn{2}{|c|}{$99 \pm 13$} & $0.009 \pm 0.002$ & $68 \pm 4$ & & $1 \cdot 68 \pm 0 \cdot 21$ \\
\hline
\end{tabular}

Values are mean \pm S.E.M., where $n$ indicates the number of different pups. Data were compared by ANOVA with Tukey's multiple-comparisons test. ${ }^{*} P<0.05$ compared with control; ${ }^{* *} P<0.01$ compared with saline-treated group; ${ }^{\dagger} P<0.05$ compared with control animals; PRA: plasma renin activity. 
in the RAAS are implicated in programmed elevations of blood pressure: for example, $\mathrm{AT}_{1}$-receptor antagonism in early postnatal life prevents development of hypertension after maternal dietary restriction in the rat (Sherman \& Langley-Evans 1998). Acute administration of a pressor dose of the hormone assesses immediate, $\mathrm{AT}_{1}$-receptormediated changes in steroidogenesis and vasoconstriction. Adrenal sensitivity to Ang II was not different, as indicated by similar elevation of aldosterone levels in both groups. Continuous infusion of Ang II below the threshold required for an immediate vasoconstrictor response is a widely used protocol for investigating long-term pressor effects, including hypertrophy and hyperplasia of smooth muscle cells in resistance arteries (Griffin et al. 1991, Su et al. 1998). Over this time course, elevated aldosterone levels are not sustained, although PRA was markedly suppressed, reflecting adrenal compensation for high Ang II levels, as is well recognised. Importantly, however, aldosterone levels were higher in Dex-treated animals at baseline and after Ang II, and PRA was not suppressed in the face of systemic hypertension. This suggests that there is increased RAAS activity in the basal state in the Dex-programmed animals, either as a result of a primary abnormality of renin secretion or perhaps secondary to sympathetic nervous system activation (Pladys et al. 2004). This is consistent with previous results with a different Dex paradigm in the rat, suggesting programming of increased RAAS activity (O'Regan et al. 2004). It is surprising, however, that Ang II-mediated suppression of PRA is increased in rats exposed to Dex in utero. The mechanism responsible for this alteration cannot be identified in the present study, although it may relate to higher blood pressure response with increased renal perfusion pressure.

The lack of effect of Dex on pressor responses to acute Ang II, consistent with the data from isolated vessels, supports the conclusion that receptor-mediated contraction is not enhanced after prenatal exposure to Dex. Chronic Ang II infusion, in contrast, produced an enhanced blood pressure elevation in the Dex group, indicating a greater sensitivity to Ang II. This could not be attributed to vascular remodelling, as the medial area was unchanged in resistance arteries. It is possible that the increased sensitivity to chronic Ang II is due to glucocorticoid-mediated sensitisation of contractile signal transduction (Hai et al. 2002) and/or free radical formation and inhibition of endothelium-derived nitric oxide (Rajagopalan et al. 1996), mediated in part by $\mathrm{AT}_{1^{-}}$ receptors (McEwan et al. 1998). Alternatively, since there is evidence of activation of the RAAS programmed by glucocorticoids, there may be increased sodium retention during chronic Ang II infusion. These mechanisms will require further studies, but the combination of lack of enhanced acute pressor response to Ang II and lack of vascular remodelling during chronic Ang II infusion does not suggest that altered structure or function of resistance vessels underlies glucocorticoid-programmed hypertension.

\section{Funding}

This work was supported by grants from the British Heart Foundation (P W F H and B R W), Wellcome Trust (J R S) and Medical Research Council (C J K).

\section{Acknowledgements}

We thank Dr J J Morton for providing reagents for plasma renin assays and Sharon Rossiter for blood pressure measurements. The authors declare that there is no conflict of interest that would prejudice the impartiality of this scientific work.

\section{References}

Anwar MA, Schwab M, Poston L \& Nathanielsz PW 1999 Betamethasone-mediated vascular dysfunction and changes in hematological profile in the ovine fetus. American Journal of Physiology. Heart and Circulation Physiology 276 H1137-H1143.

Barker DJ, Gluckman PD, Godfrey KM, Harding JE, Owens JA \& Robinson JS 1993 Fetal nutrition and cardiovascular disease in adult life. Lancet 341 938-941.

Barker DJP, Bull AR, Osmond C \& Simmonds SJ 1990 Fetal and placental size and risk of hypertension in adult life. British Medical Journal 301 259-262.

Benediktsson R, Lindsay RS, Noble J, Seckl JR \& Edwards CRW 1993 Glucocorticoid exposure in utero: new model for adult hypertension. Lancet 341 339-341.

Brown AJ, Casalsstenzel J, Gofford S, Lever A \& Morton JJ 1981 Comparison of fast and slow pressor effects of angiotensin II in the conscious rat. American Journal of Physiology 241 H381-H388.

Docherty CC, Kalmar-Nagy J, Engelen M, Koenen SV, Nijland M, Kuc RE, Davenport AP \& Nathanielsz PW 2001 Effect of in vivo fetal infusion of dexamethasone at $0.75 \mathrm{GA}$ on fetal ovine resistance artery response to ET-1. American Journal of Physiology. Regulatory Integrative and Comparative Physiology 281 R261-R268.

Dodic M, May CN, Wintour EM \& Coghlan JP 1998 An early prenatal exposure to excess glucocorticoid leads to hypertensive offspring in sheep. Clinical Science 94 149-155.

Edwards CRW, Benediktsson R, Lindsay RS \& Seckl JR 1993 Dysfunction of placental glucocorticoid barrier: link between fetal environment and adult hypertension? Lancet 341 355-357.

Evans AL, Brown W, Kenyon CJ, Maxted KJ \& Smith DM 1994 An improved system for measuring blood pressure in the conscious rat. Medical and Biological Engineering and Computing 32 101-102.

Falloon BJ, Stephens N, Tulip JR \& Heagerty AM 1995 Comparison of small artery sensitivity and morphology in pressurised and wire-mounted preparations. American Journal of Physiology 268 H670-H678.

Fowden AL 1995 Endocrine regulation of fetal growth. Reproduction, Fertility, and Development 7 351-363.

Gao Y, Zhou H \& Raj JU 1996 Antenatal betamethasone therapy potentiates nitric oxide-mediated relaxation of preterm ovine coronary arteries. American Journal of Physiology. Heart and Circulation Physiology 270 538-544. 
Griffin SA, Brown WCB, MacPherson F, McGrath JC, Wilson VG, Mulvany MJ \& Lever AF 1991 Angiotensin II causes vascular hypertrophy in part by a non-pressor mechanism. Hypertension 17 626-635.

Hai CM, Sandowska G, Francois L \& Stonestreet BS 2002 Maternal dexamethasone treatment alters myosin isoform expression and contractile dynamics in fetal arteries. American Journal of Physiology. Heart and Circulation Physiology 283 H1743-H1749.

Haigh RM, Jones CT \& Milligan G 1990 Glucocorticoids regulate the amount of $G$ proteins in rat aorta. Journal of Molecular Endocrinology 5 185-188.

Johns DG, Dorrance AM, Tramontini NL \& Webb RC 2001 Glucocorticoids inhibit tetrahydrobiopterin-dependent endothelial function. Experimental Biology and Medicine 226 27-31.

Kenyon CJ, Panarelli M, Holloway CD, Dunlop D, Morton JJ, Connell JMC \& Fraser R 1993 The role of glucocorticoid activity in the inheritance of hypertension: studies in the rat. Journal of Steroid Biochemistry and Molecular Biology 45 7-11.

Khan I, Dekou V, Hanson M, Poston L \& Taylor P 2004 Predictive adaptive responses to maternal high-fat diet prevent endothelial dysfunction but not hypertension in adult rat offspring. Circulation 110 1097-1102.

Khan IY, Dekou V, Douglas G, Jensen R, Hanson MA, Poston L \& Taylor PD 2005 A high-fat diet during rat pregnancy or suckling induces cardiovascular dysfunction in adult offspring. American Journal of Physiology. Regulatory Integrative and Comparative Physiology 288 R127-R133.

Khan LY, Taylor PD, Dekou V, Seed PT, Lakasing L, Graham D, Dominiczak AF, Hanson MA \& Poston L 2003 Gender-linked hypertension in offspring of lard-fed pregnant rat. Hypertension 41 168-175.

Lamireau D, Nuyt AM, Hou X, Bernier S, Beauchamp M, Gobeil F, Lahaie I, Varma DR \& Chemtob S 2002 Altered vascular function in fetal programming of hypertension. Stroke 33 2992-2998.

Langley-Evans SC, Phillips GJ \& Jackson AA 1994 In utero exposure to maternal low protein diets induces hypertension in weanling rats, independently of maternal blood pressure changes. Clinical Nutrition 13 319-324.

Langley-Evans SC, Phillips GJ, Benediktsson R, Gardner, DS, Edwards CW, Jackson AA \& Seckl JR 1996 Protein intake in pregnancy, placental glucocorticoid metabolism and the programming of hypertension in the rat. Placenta 17 169-172.

Lesage J, Blondeau B, Grino M, Breant B \& Dupouy JP 2001 Maternal undernutrition during late gestation induces foetal over-exposure to glucocorticoids and intra-uterine growth retardation, and disturbs the hypothalamic-pituitary adrenal axis in the newborn rat. Endocrinology 142 1692-1702.

Lindsay RS, Lindsay RM, Waddell BJ \& Seckl JR 1996 Prenatal glucocorticoid exposure leads to offspring hyperglycaemia in the rat: studies with the $11 \beta$-hydroxysteroid dehydrogenase inhibitor carbenoxolone. Diabetologia 39 1299-1305.

Martin W, Furchgott RF, Villani GM \& Jothianadan D 1986 Depression of contractile responses in rat aorta by spontaneously released endothelium-derived relaxing factor. Journal of Pharmacology and Experimental Therapeutics 237 529-538.

McEwan PE, Gray GA, Sherry L, Webb DJ \& Kenyon CJ 1998 Differential effects of angiotensin II on cardiac cell proliferation and intramyocardial perivascular fibrosis in vivo. Circulation 98 2765-2773.

Miller JA, Leckie BJ \& Morton JJ 1980 A micro-assay for active and total renin concentration in human plasma based on antibody trapping. Clinica Chimica Acta 101 5-15.

Nyirenda MJ \& Seckl JR 1998 Intrauterine events and the programming of adulthood disease: the role of fetal glucocorticoid exposure (Review). International Journal of Molecular Medicine $2607-614$.

Nyirenda MJ, Lindsay RS, Kenyon CJ, Burchell A \& Seckl JR 1998 Glucocorticoid exposure in late gestation permanently programs rat hepatic phosphoenolpyruvate carboxykinase and glucocorticoid receptor expression and causes glucose intolerance in adult offspring. Journal of Clinical Investigation 101 2174-2181.

O’Regan D, Kenyon CJ, Seckl JR \& Holmes MC 2004 Glucocorticoid exposure in late gestation in the rat permanently programs gender-specific differences in adult cardiovascular and metabolic physiology. American Journal of Physiology. Endocrinology and Metabolism 287 E863-E870.

Ortiz LA, Quan A, Zarzar F, Weinberg A \& Baum M 2003 Prenatal dexamethasone programs hypertension and renal injury in the rat. Hypertension 41 328-334.

Ozaki T, Nishina H, Hanson MA \& Poston L 2001 Dietary restriction in pregnant rats causes gender-related hypertension and vascular dysfunction in offspring. Journal of Physiology 530 141-152.

Pladys P, Lahaie I, Cambonie G, Thibault G, Le NLO, Abran D \& Nuyt AM 2004 Role of brain and peripheral angiotensin II in hypertension and altered arterial baroreflex programmed during fetal life in rat. Pediatric Research 55 1042-1049.

Rajagopalan S, Kurz S, Munzel M, Tarpey M, Freeman BA, Griendling KK \& Harrison DG 1996 Angiotensin II-mediated hypertension in the rat increases vascular superoxide production via membrane NADH/NADPH oxidase activation. Contribution to alterations in vasomotor tone. Journal of Clinical Investigation 97 1916-1923.

Sato A, Suzuki H, Iwata Y, Nakazato Y, Kato H \& Saruta T 1992 Potentiation of inositol trisphosphate production by dexamethasone. Hypertension 19 109-115.

Sherman RC \& Langley-Evans SC 1998 Early administration of angiotensin-converting enzyme inhibitor captopril prevents the development of hypertension programmed by intrauterine exposure to a maternal low-protein diet in the rat. Clinical Science 94 373-381.

Smith JM, Jones SB, Bylund DB \& Jones AW 1987 Characterization of the alpha-1 adrenergic receptors in the thoracic aorta of control and aldosterone hypertensive rats: correlation of radioligand binding with potassium efflux and contraction. Journal of Pharmacology and Experimental Therapeutics 241 882-890.

Smith L \& Smith JB 1994 Regulation of the sodium-calcium exchanger by glucocorticoids and growth factors in vascular smooth muscle cells. Journal of Biological Chemistry 269 27527-27531.

Souness GW, Brem AS \& Morris DJ 200211 beta-Hydroxysteroid dehydrogenase antisense affects vascular contractile response and glucocorticoid metabolism. Steroids 67 195-201.

Su EJ, Lombardi DM, Siegal J \& Schwartz SM 1998 Angiotensin II induces vascular smooth muscle cell replication independent of blood pressure. Hypertension 31 1331-1337.

Torrens C, Brawley L, Barker AC, Itoh S, Poston L \& Hanson MA 2003 Maternal protein restriction in the rat impairs resistance artery but not conduit artery function in pregnant offspring. Journal of Physiology 547 77-84.

Ullian ME 1999 The role of corticosteroids in the regulation of vascular tone. Cardiovascular Research 41 55-64.

Ullian ME, Schelling JR \& Linas SL 1992 Aldosterone enhances angiotensin II receptor binding and inositol phosphate responses. Hypertension 20 67-73.

Ullian ME, Walsh LG \& Morinelli TA 1996 Potentiation of angiotensin II action by corticosteroids in vascular tissue. Cardiovascular Research 32 266-273.

Woodall SM, Johnston BM, Breier BH \& Gluckman PD 1996 Chronic maternal undernutrition in the rat leads to delayed postnatal growth and elevated blood pressure of offspring. Pediatric Research 40 438-443.

Received 7 November 2005

Accepted 9 December 2005

Made available online as an Accepted Preprint

12 December 2005 